\title{
Perceptions of undergraduate Graphic Design students on the educational potential of Facebook
}

\author{
Nicos Souleles* \\ Department of Multimedia and Graphic Arts, Faculty of Applied Arts and Communication, \\ Cyprus University of Technology, Lemesos, Cyprus
}

(Received 20 February 2012; final version received 28 May 2012)

The popularity of Facebook among university students inevitably raises questions on the educational potential of this Social Networking Site for Higher Education. From the limited literature on the instructional uses of Facebook, one can draw conflicting conclusions. Benefits were identified through the communicative potential, student participation in study groups and through informal learning, i.e. learning that takes place outside the formal structures of the learning environment. In contrast, it is also argued that the instructional benefits of Facebook are not straightforward. This phenomenographic investigation examines the perceptions of undergraduate Graphic Design students in a higher education institution in Cyprus, on the use of Facebook for teaching and learning. Characteristic of Art and Design education is the centrality of the studio and student self-reflection. Despite some literature that considers Facebook provides a viable alternative to the physical studio, the participants in this investigation expressed a preference for face-to-face instruction and consider Facebook as complimenting rather than replacing studio practices. Some participants benefited from the use of Facebook by joining support groups and exploring information relevant to their studies. Further research can investigate how Facebook can be embedded in studio-based teaching and learning.

Keywords: Facebook; Graphic Design; teaching and learning; informal learning; studio

\section{Introduction}

Various studies emphasise that Social Networking Sites (SNSs) and in particular, Facebook are popular among the wider student population. For example, Cain (2008, p. 1) estimated that $80-90 \%$ of United States college students use Facebook. In 2010, a survey of 812 university students at the University of South Australia found that $91.1 \%$ of them were active users of Facebook (Vivian 2011, p. 255). Similarly, Junco (2011, p. 1) asserts that from 126 universities in the US and one Canadian, 90\% of students used SNSs and 97\% said they used Facebook. Similarly, it was claimed that in 2008 about $95 \%$ of British undergraduate students regularly used SNSs (Madge et al. 2009, p. 141). There are also claims that students are "addicted" to Facebook (Sheldon 2008, p. 40), and that they prefer to use this SNS than the

\footnotetext{
*Email: nicos.souleles@cut.ac.cy

RLT 2012. (C) 2012 N. Souleles. Research in Learning Technology is the journal of the Association for Learning Technology 241

(ALT), a UK-based professional and scholarly society and membership organisation. ALT is registered charity number 1063519. http://www.alt.ac.uk/. This is an Open Access article distributed under the terms of the Creative Commons "Attribution 3.0

Unported (CC BY 3.0)" license (http://creativecommons.org/licenses/by/3.0/) permitting use, reuse, distribution and transmission, and reproduction in any medium, provided the original work is properly cited. 
institutional Virtual Learning Environment (VLE) (Bosch 2009, p. 191). One author went as far as stating that "Facebook owns your campus" (Selwyn 2007).

The widespread use of SNSs among undergraduate students poses a number of interrelated questions such as what are the educational affordances possible with Facebook and how do undergraduate students consider its use in instructional contexts. As these questions are pertinent for Higher Education (HE) in general, they are also relevant for Art and Design education. This paper explores the perceptions of undergraduate Graphic Design students vis-à-vis their views on the educational affordances possible with Facebook for teaching and learning. It is a phenomenographic investigation that aims to capture the range of views and experiences of these students. Prosser and Trigwell (2000) provide a useful rationale for the value of researching student views on aspects of teaching and learning. The authors argue that teaching and learning are closely related and the required alignment is between the lecturer's and the student's perception of teaching. The latter bring to the instructional process their conceptions and prior experiences that need to be considered for effective instruction to take place.

\section{Literature review}

There is little research that agrees on the educational potential of Facebook in HE (Anouk 2010; Boyd and Ellison 2007; Junko 2011). Increasingly, however, this picture is evolving as more research is undertaken in an attempt to further unpack the instructional potential of SNSs.

Bosch (2009) investigated how the students of a South African university use Facebook, and how teachers attempt to engage students through this SNS. The author argued that the generation of youth often described as "digital natives", might be resistant to traditional methods of instruction and need more interactive environments. He concluded that Facebook could provide for efficient and exciting means of communication between teachers and students.

Selwyn (2007, p. 6) examined the reasons university students use Facebook and which aspects of their interactions relate to education per se. He resolved that in the multimodal communication environment of Facebook the majority of messages relate to keeping up with friends while education related exchanges represented only a small percentage and subsequently concluded that Facebook does not merit any particular consideration by educators nor does it represent any cause for "moral panic" (Selwyn 2007, pp. 17-22).

On a similar note, Cheung and Vogel (2011) inquired into the effectiveness of Facebook in HE to enhance the relationship between students and teachers, and the factors that affect whether students choose or not to use Facebook to communicate with teachers. The authors refer to "social capital" theory, a concept addressed by a number of researchers (Bosch 2009, p. 188; Ellison, Steinfield and Lampe 2007). In brief, social capital theory relates to the actual or virtual benefits or resources that one accrues from relationships with other people (Cheung and Vogel 2011, pp. 386-387). In their investigation, the authors found a positive connection between social capital and intensity of Facebook use. Students with high intensity use are more willing to communicate with their teachers for academic matters and thus benefit from such exchanges (Cheung and Vogel 2011, p. 396). This finding is similar to that of Ellison, Steinfield and Lampe (2007, p. 1164), who argues that 
Internet use alone does not predict social capital accumulation but intensive use of Facebook does.

Karl and Peluchette (2011, p. 220) caution against student-teacher communication through Facebook, as many students feel uncomfortable to become friends with teachers. "... they [students] would feel nervous, worried, suspicious, and concerned if they received a friend request from a professor ... it is not appropriate for faculty to initiate such requests ..." (Karl and Peluchette 2011, p. 220). The authors recommend that student-teacher exchanges through SNSs ideally should be preceded by an explanation in the class as to the reason for the friend request, and a clarification that Facebook would be used for teaching and learning and not as a surveillance tool (Karl and Peluchette 2011, p. 220). On a similar note, Madge et al. (2009) showed that $53 \%$ of students who participated in a survey were positive about the use of Facebook for teaching and learning as long as the focus was on administrative matters such as queries, lecture notes, notices, etc. Students were not overly keen for teachers to deal with pedagogic issues because they consider Facebook as a social space and not a teaching and learning environment (Madge et al. 2009, pp. 150-151). This however does not concur with the position of Roblyer et al. (2010) who conducted a small-scale survey on how student and teacher perspectives compare, and concluded that the two differ with the former more open than the latter to the idea of using Facebook for instructional purposes (Roblyer et al. 2010, p. 138).

Some benefits were identified in the limited research on the use of SNSs for teaching and learning as well as some concerns. A study by Minocha (2009) that covered 26 different initiatives in HE and Further Education and involved the use of different SNSs (MySpace, Facebook, Flickr, YouTube, Second Life, Blogger and Wikis), identified a wide range of applications for teaching and learning. These include group work, collaborative collection of resources, recording of group discussions for access after classes, giving control of learning to students through peer-assessment and self-assessment, simulating work environments, reflective learning such as commenting on blogs and engaging in discussion, problem and inquiry-based learning and improving the effectiveness of face-to-face tutorials and seminars through student contributions and questions that helped the tutor to effectively plan tutorials (Minocha 2009, pp. 24-26).

Maloney (2007) adopts an enthusiastic approach in his assessment of the educational potential of SNSs. He argues that early e-learning technologies were good at content delivery, evaluation, and communication, but with Web 2.0 there is renewed focus on innovation, creation, collaboration, knowledge management and social interaction. This, he suggests, mirrors much of what we know to be good for teaching and learning, such as collaborative learning and active student participation.

Bosch (2009, pp. 195-196) considers that the instructional benefits relate to the communicative potential of Facebook and in particular the ease with which students can identify and share among themselves learning material, as well as ask questions that they feel uncomfortable to pose in the class. Similarly, Cheung and Vogel (2011, p. 396) argue for the communicative potential but only for students with a high intensity use for they are more likely to use Facebook for academic and projectrelated issues.

A more critical view is that put forward by Selwyn (2011). Firstly, he recognises that the conversational, collaborative and communal dimensions of Facebook are 
what the enthusiasts value. However, he cautions that the educational benefits are not straightforward for student engagement with Facebook is "profoundly informal" and "often at a tangent with the official learning aims of educators". Much of the learning that takes place on Facebook compares to the learning that takes place in the corridors, in the cafeterias and in after-school telephone conversations (Selwyn 2011, pp. 4-5). While Selwyn (2011) is dismissive of the possibility that some form of meaningful learning can occur with SNSs and emphasises the central role of educators in teaching and learning, for Siemens and Weller (2011, p. 166) this represents the traditional hierarchical structures of HE learning. Such structures are antithetical to learning facilitated by SNSs that is characterized by "attributes of autonomy, reduced resistance to information flow, ease of connectivity, organic growth, rapid iteration and improvement of ideas and concepts".

Lastly, a number of authors associate student use of SNSs with informal learning, i.e. learning that happens outside the formal educational system and is often unstructured and unintentional. For Madge et al. (2009, p. 152) it is clear that Facebook provides an environment for informal learning that encompasses a range of skills such as team working and organizational competencies, all of which are useful for employability. Although she recommends further research, the author urges teachers to recognize the skills students can develop as a consequence of Facebook use. Likewise, Vivian (2011, p. 256) too, urges for further research into the relationship between SNSs and informal learning so that teachers can be informed about how to effectively incorporate this technology into teaching and learning. She contends that student use of SNSs supports informal learning through the facilitation of collaboration, group work, discussions, revisions and the formation of study groups.

Appealing for more research into the connections between educational technology and informal learning environments, Schwier (2010, pp. 90-91) makes a passionate plea for the instructional value of the latter. Similarly to Siemens and Weller (2011) above, she compares the formal educational contexts that are institutionally bound to a graduating system of certification, against learning that takes place in society through a variety of activities that may not entail a content expert. Such learning is unorganized, it is not systemic and at times, it can be unintentional and overall has an amorphous path (Schwier 2010, p. 91).

\section{SNSs and Art and Design education}

A brief reference to some of the main tenets of Art and Design education and in particular, the role of the studio and student self-reflection are of relevance to this paper for they provide a context and a point of reference vis-à-vis some of the potential instructional benefits of Facebook. Art and Design disciplines share a number of common teaching and learning practices that are characteristic to the sector. The Art and Design Benchmark Statement (Kennedy and Welch 2008, pp. 2-3) describes these in the following manner:

Learning in art and design develops ... [the ability] of reflecting on one's own learning and development ... Most students work in studio environments supported by a wide range of workshops and other dedicated facilities.

The centrality of self-reflection for teaching and learning in Art and Design is rationalised based on supporting intellectual thought and understanding of one's practices: 
... an understanding of the context of the practice is essential ... it enhances [student] intellect through critical awareness and by locating the individual in an historical continuum ... it provides knowledge of how an individual's practice relates to that of others, which is the cornerstone of originality and personal expression. (Kennedy and Welch 2008, p. 4)

Ellmers (2006, p. 1) contends that the limited research in Graphic Design education contributes to the loss of learning opportunities and more specifically the constructive role reflection plays towards enhancing learning outcomes. Reflective assessment tasks encourage students to recognise critical incidents from the design process and gives them a context to consider the outcomes of the final design artefact. The significance of this is that students assume responsibility for judging the important steps of the design process and this encourages them to become independent learners (Ellmers 2006, p. 7).

In a study by Morkel (2011), the traditional function of the design studio is defined as a physical space where learning is supported through social interactions on three levels. In the physical space of the studio students engage in conversations with the self (internal dialogue), they consult with peers (horizontal dialogue) and they discuss with teachers (vertical dialogue). The author argues that increasingly, due to pressures on teachers and diminishing resources, some HE institutions are finding it difficult to sustain a vibrant design studio environment. Therefore, teaching and learning started to extend beyond the physical design studio to an online virtual space that is distributed across space and time. SNSs provide an alternative studio milieu that replicates effortlessly the physical learning environment and in particular interaction, communication and dialogue (Morkel 2011; Schadewitz and Zamenopoulos 2009).

Park and Kastanis (2009) examined the instructional value of Facebook in a learning design environment. The authors highlight a common concern of design educators, the questionable attitude of some students to focus on the acquisition of technical skills to the detriment of developing and acquiring critical thinking competencies. Park and Kastanis (2009) argue that SNSs can be used to facilitate and enrich "socially-mediated reflection" if student participatory activities and social interactions are embedded in curricula through a systemic, well-thought and meaningful manner as part of a holistic learning experience.

Although more studies are needed to firmly establish the instructional potential and specific challenges for Art and Design education, what can be asserted from the above, is that in some cases SNSs, provide for a virtual environment that can compliment some of the activities that take place in the physical studio including student self-reflection and dialogue with peers and teachers.

\section{Methodology, delimitations and limitations}

The objective of this paper is to investigate the range of perceptions undergraduate Graphic Design students have on the instructional potential of Facebook. It is a qualitative and interpretivist investigation pursued through semi-structured interviews, which is the main tool of phenomenography. The premise of such studies is that we cannot separate the structure and the content of the experience from one another. Marton (1981) makes the distinction between research methodologies that deal with "first-order perspective", i.e. the aim is to describe various aspects of the world, and "second-order perspective", i.e. the description of people's experiences of 
aspects of the world. The assumption of phenomenographic research is the existence of a finite number of different ways of perceiving a particular phenomenon and the outcome of such research comprises thematic categories of description of the various conceptions of a phenomenon (Akerlind 2005). It may appear that such studies deal with too wide a scope, however, this is the purpose in particular when one is investigating under-researched areas, to provide an overview, a first stepping-stone for further research to follow (Souleles 2012).

The critique of phenomenography vis-à-vis validity comes from both quantitative (grounded in interpretivist research tradition) and qualitative (normative) perspectives. The former question the role of the interviewee, the subjectivity of establishing an outcome space that consists of categories of description and the credibility of such findings. For example, Webb (1997) argues that phenomenographers fail to account for their own prejudices and the part these play in the construction of people's perceptions; observations are always preceded by theory (Webb 1997, p. 200). The qualitative critique consists of arguments in support of other longer established methodologies, of which phenomenography is an "errant branch" (Entwistle 1997, p. 128).

The main delimitation of this investigation is that it encompasses only Graphic Design and not a combination of various design disciplines. The Art and Design Benchmark Statement (Buss and Gretton 2002, p. 4) identifies the following generic areas within Art and Design: fashion/textiles, fine art, Graphic Design, photography/ film/television, three-dimensional design, general art and design, media production, as well as programmes that focus on a "distinctive area of academic study or professional practice", such as contemporary applied arts and interior design (Buss and Gretton 2002, p. 4). Inevitably, all these disciplines involve some degree of ICT use, including dedicated software. However, this study excludes disciplines where the curricula necessitates the exclusive use of ICTs, such as media production (film, television) and multimedia design. In addition, it excludes disciplines such as Fine Arts where the use of ICTs tends to be peripheral and studio teaching and learning methods comprise mostly of hands-on practice with various non-ICT related tools and material.

This investigation does not consider gender differences in the use of SNSs and it needs to be acknowledged that there is some relevant literature. For example, in a study conducted by Joinson (2008) the author concluded that female users in comparison to males tend to use SNSs more for the purpose of promoting social connections and uploading photographs.

The limitation of this investigation relates to the parameters of the phenomenographic method as described above, i.e. the generalizability and utility of findings that are the result of the research paradigm. This relates directly to the inability to draw descriptive or inferential conclusions from the sample data of this investigation about the wider group of undergraduate Graphic Design students and their perception of the instructional potential of Facebook.

In terms of ethical issues considered in the conduct of this investigation, students were informed that the information they provided would only be used for the purpose of this study and their informed consent was sought before interviews took place. It was made clear to them that their anonymity will be respected. After interviews were conducted, transcripts were forwarded to the interviewees to confirm their respective accounts. 


\section{Categories of perceptions}

The data for this investigation was gathered through 15 interviews with undergraduate Graphic Design students in the same university but at different years of their programme of study. All interviews were recorded and then entered into Atlas.ti (qualitative data analysis software). Subsequently, the transcripts were analysed, coded and categorised according to emerging themes. The latter were grouped as answers to their corresponding questions as listed in the Appendix.

\section{Frequency of use}

Without exception, all interviewees stated that they use Facebook every day but the time they spend with it varied greatly. It was possible to distinguish different groups in terms of the amount of time each one spends in Facebook on a daily basis. At the bottom of the scale are interviewees who log in Facebook for a few minutes each day. Characteristic of this group is the statement: "I can't be bothered ... I have a quick look to see if there are any messages for me and I log out" (Interviewee 5). At the top of the scale are those who spend up to eight hours daily. In between these two groups, the variation ranges from a maximum of one to seven hours on a daily basis. Common characteristic of the interviewees who spend more than one hour each day is that they are not continuously using Facebook but rather they remain logged in while engaged with other activities. Characteristic is the statement:

I can say that I keep Facebook open between six to eight hours every day but I don't use it all the time. I simply keep it open. If I want to use Facebook or ask something, then

I want to be on standby. (Interviewee 1)

This finding, i.e. the frequency of Facebook use by undergraduate Graphic Design students, is consistent with the literature that suggests the use of this SNS is popular among the wider student population. However, there is no obvious agreement among the interviewees as to what constitutes excessive use of Facebook. For example, one interviewee who spends up to eight hours per day on Facebook expressed the view that this constitutes excessive use, which is also the view of another who spends up to two hours every day. In terms of the association between social capital accumulation which is a product of intensive Facebook use and willingness to communicate with teachers for academic matters (Cheung and Vogel 2011), the varied frequency of use suggests an uneven distribution of potential educational benefits. Part of the answer to this unevenness in the frequency of use lies with students who are not keen for teachers to use Facebook for teaching and learning as they consider the latter primarily a social space (Madge et al. 2009).

\section{Form and pattern of use}

It is possible to distinguish four different groups of activities that encompass what the interviewees do when they use Facebook. The first group consists of those who only or predominantly engage in one kind of Facebook activity, such as chatting, uploading photos, or checking notices by friends. In the second group are those who carry out two different kinds of activities and these can vary. For example, some interviewees like to chat and play games, while others check photos and notices but do not like to play games or chat. Similarly to the previous group, in the third group are the interviewees who combine three different kinds of activities in Facebook, 


\section{N. Souleles}

and once again these activities can vary. For example, some interviewees like to chat, upload photos and play games, while others like to share music, check notices and chat. Lastly, it is characteristic of the fourth group that they use as many as possible of the varied activities available in Facebook. What can be inferred from the above is that the pattern of Facebook activities is varied among the interviewees. The following two statements are indicative of the difference in form and pattern of Facebook use among the interviewees: "I am only interested in chatting to my friends and I don't like playing games or uploading photos" (Interviewee 8); "There is so much to do ... I like chatting, playing games, looking at photos, checking what my friends are up to ..." (Interviewee 3 ).

Although not explicitly stated by the interviewees, low frequency of use assumes less diversity in the form and pattern of Facebook use, which in turn contributes to decreased social capital accumulation. However, it cannot be argued that the same assumptions as with frequency of use (above), apply here too, i.e. diverse form and pattern of use implies more opportunities for student-teacher exchanges. Some Facebook activities such as sharing photos and chatting can provide more opportunities for formative feedback compared to playing games and sharing interests in music.

\section{Effect on studies}

This investigation identified four distinct themes on how the interviewees consider the overall impact of Facebook use on their studies. The first group considers that Facebook use has no influence, neither positive nor negative on their studies. Indicative is the statement: "I use Facebook when I don't have any homework ... I don't let it [affect my studies]" (Interviewee 11). The second group considers Facebook as a positive influence on their studies and characteristic of this theme is the statement: "It [Facebook] helped me keep in touch with other students ... I can communicate with my classmates" (Interviewee 13). In the third group the negative impact of Facebook on the studies of the Interviewees is made explicit. For example, "I consider it detrimental for my studies ... I could have been doing other things ... but I continue ..." (Interviewee 15). Lastly, there are interviewees who consider that there is both positive and negative potential in terms of how Facebook use impacts their studies. Characteristic of this latter group is the statement: "For some things it [Facebook] is negative ... I spend too much time on Facebook and it takes away from my study time. The positive is that I can ask questions when I have problems" (Interviewee 14).

Similarly to the form and pattern of Facebook activities that is varied among the interviewees, so too are the views about the effects on their studies. Significantly however, when the question is posed in general terms, the dominant theme is recognition among some of the interviewees that the benefits relate to the communicative potential possible through Facebook.

\section{Help with studies}

In the first group interviewees expressed the opinion that Facebook can offer nothing useful and indicative of this theme is the statement: "There are other things that can help me more and not Facebook" (Interviewee 8). Characteristic of the second group is the recognition that some help is possible based on the ease of posting and accessing notices with administrative content. For example, the statement: 
"It [Facebook] can allow for important notices and announcements to be made available to all of us [students]. Nothing else" (Interviewee 13). Characteristic of the third group is that there are interviewees who have found diverse ways of using Facebook to help them with their studies, such as uploading their work in Facebook and receiving formative feedback from peers and teachers, searching and joining Facebook groups relevant to their studies and forming study groups to support each other. Indicative of this theme is the statement: "Yes, it [Facebook] can be helpful because there are groups that are relevant to my studies. One can get ideas, information. One can see what other designers do" (Interviewee 15).

It can be inferred from the above that for the interviewees whose frequency, form and pattern of use included the identification of relevant information and the use of a variety of activities possible through Facebook to support their studies, there were some benefits. This is in contrast to the interviewees who for whatever reason did not attempt to explore Facebook for purposes relevant to their studies. It cannot be discounted that one of the reasons for this is the view held by some students that Facebook is a social space and not a teaching and learning environment.

\section{Use of Facebook for teaching and learning}

Three themes emerged on how interviewees consider the use of Facebook in formal teaching and learning contexts. In the first group there was expressed resistance to any notion of teachers using Facebook as part of the instructional process. Characteristic of this view is the statement: "I don't like the idea of teachers using Facebook [for teaching and learning]. It is only for my own personal things and my friends" (Interviewee 10). In the second group are interviewees who consider Facebook use by teachers can be useful but only when implemented in a limited manner. For example, the statement: "We shouldn't depend too much on it for our lessons. It is useful for some things ... we can use it to vote or express a collective opinion on something" (Interviewee 13). Lastly, some interviewees were enthusiastic about the prospect of teachers embedding Facebook use in teaching and learning. Indicative of this theme is the statement: "I think if teachers started using Facebook [for teaching and learning] they will get closer to us because young people and students like using it" (Interviewee 9).

The above themes confirm the division identified in the literature review between students who perceive Facebook as a private social space not to be used as part of the formal instructional process (Madge et al. 2009), and those who are not concerned and may even welcome the latter (Roblyer et al. 2010). Further studies can examine under what circumstances it may be possible to convince the former about the educational benefits of Facebook for teaching and learning.

\section{Useful information in Facebook}

The interviewees were asked to elaborate on whether they made an effort to search in Facebook for information that is relevant to their studies. Once again, three themes emerged. Firstly, a group of interviewees expressed the opinion that they did not explore this option. The statement represents this: "I haven't looked into it and nobody told me anything about it" (Interviewee 9). The second group consists of interviewees who searched for useful information but concluded that there was none. For example, "I looked into it but there was nothing I could use" (Interviewee 11). 
Lastly, the third group consists of those who have explored Facebook to find useful information relating to their studies and this is encompassed in the view: "Some of the information is very useful especially if one makes an effort. There are lots of interesting groups and information" (Interviewee 5).

The interviewees who searched for relevant and useful information available through Facebook, are likely to have benefited from informal learning similarly to those who formed study and support groups using this SNS. Some of the interviewees stated that they were not aware that there is information in Facebook relevant to their studies and this points to the option for teachers to provide an induction programme that addresses this gap.

\section{Facebook versus physical studio}

Two distinct themes were identified on how the interviewees consider Facebook as an alternative or complimentary to studio teaching and learning. In the first group belong those who are against the notion that Facebook can replace or replicate the learning that takes place in the physical studio. Characteristic is the statement: "Facebook does not provide real contact with classmates and teachers. I prefer faceto-face contact because it helps me to reflect better on my work" (Interviewee 14). In the second group are interviewees who are prepared to accept some role for Facebook and are not completely dismissive of the idea but still view the physical studio as a necessity. Indicative of the latter is the statement: "I don't think Facebook can replace the physical design studio but it can compliment it. Personally I prefer face-to-face contact" (Interviewee 4).

The preference for face-to-face contact through learning activities carried out in the physical studio is the common denominator between both of the above groups, for not a single interviewee welcomed the idea of completely replacing the studio with Facebook. However, to the extent that teachers are able to structure through Facebook activities that promote socially mediated reflection (Park and Kastanis 2009), the instructional value of this SNS as complimenting studio practices, cannot be dismissed easily.

\section{Conclusion}

The literature on the use of Facebook in HE reveals no consensus on the educational affordances possible and this indicates the need for further research. This phenomenographic investigation sought to capture the range of perceptions undergraduate Graphic Design students have on the educational potential of Facebook, for there is obvious value in incorporating student views in the planning of instruction.

The physical studio and student self-reflection are essential components of the teaching and learning practices in art and design education. Due to diminishing resources some $\mathrm{HE}$ institutions are finding it difficult to provide effective studio environments and there is some literature that supports the notion that SNS can provide an alternative solution (Morkel 2011; Park and Kastanis 2009; Schadewitz and Zamenopoulos 2009) and can support informal learning (Madge et al. 2009).

The varied frequency of use among the interviewees suggests different levels of social capital accumulation and at least to some extent the educational benefits (informal learning, formative feedback) are dependent upon individual use. The interviewees in this investigation perceive educational benefits based on the 
communicative potential of Facebook. The diversity in the form and pattern of use posses less of a challenge for not all Facebook activities promote communication and it would be possible to focus on those that do. In addition, it may not be possible to convince all students who perceive Facebook only as a social space, that there are educational benefits in exploring what this SNS offers in terms of interests groups and other useful information. However, a targeted induction or workshop can attempt to address this challenge and further research in this area in the form of action research, is certainly needed. Although a number of interviewees in this investigation consider that Facebook can compliment some teaching and learning activities that take place in the studio, there was overwhelming agreement that face-to-face contact in the studio is preferable for it facilitates better social interaction and self-reflection compared to Facebook. Lastly, there is some validity in Selwyn's (2011) argument that the educational potential of Facebook are not completely apparent, but based on this investigation with undergraduate Graphic Design students it can be argued that under certain conditions benefits exist and with further research the latter and the factors that support or hinder them, can become more explicit.

\section{References}

Akerlind, G. (2005) 'Variation and commonality in phenomenographic research methods', Higher Education Research \& Development, vol. 24, no. 4, pp. 321-334.

Anouk, L. (2010) 'Crossing the boundary: exploring the educational potential of social networking sites', Digital Humanities DH2010, [online] Available at: http://dh2010.cch. kcl.ac.uk/academic-programme/abstracts/papers/html/ab-856.html

Bosch, T. (2009) 'Using online social networking for teaching and learning: Facebook use at the University of Cape Town', Communication, vol. 35, no. 2, pp. 185-200.

Boyd, D. M. \& Ellison, N. B. (2007) 'Social network sites: definition, history, and scholarship', Journal of Computer-Mediated Communication, vol. 1, article 11.

Buss, D. \& Gretton, T. (2002) Art \& Design Benchmark Statement, The Quality Assurance Agency for Higher Education, Gloucester, UK.

Cain, J. (2008) 'Online social networking issues within academia and pharmacy education', American Journal of Pharmaceutical Education, vol. 72, no. 1, pp. 1-7.

Cheung, R. \& Vogel, D. (2011) 'Can Facebook enhance the communications between teachers and students?', The International Journal of Learning, vol. 7, no. 11, pp. 385-397.

Ellison, N. B., Steinfield, C. \& Lampe, C. (2007) 'The benefits of Facebook "Friends:" social capital and college students' use of online social network sites', Journal of ComputerMediated Communication, vol. 12, pp. 1143-1168.

Ellmers, G. (2006) 'Reflection and graphic design pedagogy: developing a reflective framework to enhance learning in a graphic design tertiary environment', University of Wollongong, [online] Available at: http://ro.uow.edu.au/creartspapers/8/

Entwistle, N. (1997) 'Introduction: phenomenography in higher education', Higher Education Research \& Development, vol. 16, no. 2, pp. 127-34.

Joinson, A. N. (2008) 'Looking at', 'Looking up' or 'Keeping up with' people? Motives and uses of Facebook', Proceedings of the 2008 26th Annual SIGCHI Conference on Human Factors in Computing Systems, New York, NY, pp. 1027-1036.

Junco, R. (2011) 'Too much face and not enough books: the relationship between multiple indices of Facebook use and academic performance', Computers in Human Behavior, [online] Available at: http://blog.reyjunco.com/publications

Karl, K. A. \& Peluchette, J. V. (2011) "“Friending” professors, parents and bosses: a Facebook connection conundrum', Journal of Education for Business, vol. 86, no. 4, pp. 214-222.

Kennedy, G. \& Welch, E., (eds) (2008) Subject Benchmark Statement, Art and Design (QAA 238 03/08), The Quality Assurance Agency for Higher Education, Gloucester, UK.

Madge, C., et al. (2009) 'Facebook, social integration and informal learning at university: "It is more for socialising and talking to friends about work than for actually doing work", Learning, Media and Technology, vol. 34, no. 2, pp. 141-155. 


\section{N. Souleles}

Maloney, E. (2007) 'What Web 2.0 can teach us about learning', The Chronicle of Higher Education, vol. 53, p. B26.

Marton, F. (1981) 'Phenomenography - describing conceptions of the world around Us', Instructional Science, vol. 10, pp. 177-200.

Minocha, S. (2009) 'A study on the effective use of social software by further and higher education in the UK to support student learning and engagement', JISC, [online] Available at: http://www.jisc.ac.uk/whatwedo/projects/socialsoftware08.aspx

Morkel, J. (2011) 'Facebook-enhanced face to face learning: the architecture studio', Proceedings of the 5th International Computer \& Instructional Technologies Symposium, FIrat University, Turkey, pp. 1-7.

Park, J. Y. \& Kastanis, L. (2009) 'Reflective learning through social network sites in design education', The International Journal of Learning, vol. 16, no. 8, pp. 11-21.

Prosser, M. \& Trigwell, K. (2000) Understanding Learning and Teaching. The Experience in Higher Education, The Society for Research into Higher Education and Open University, Buckingham.

Roblyer, M. D., et al. (2010) 'Findings on Facebook in higher education: a comparison of college faculty and student uses and perceptions of social networking sites', Internet and Higher Education, vol. 13, no. 3, pp. 134-140.

Schadewitz, N. \& Zamenopoulos, T. (2009) 'Towards an online design studio: a study of social networking in design distance learning', Proceedings of the International Association of Societies of Design Research (IASDR) Conference, Seoul, South Korea, pp. 199-208.

Schwier, R. A. (2010) 'Focusing educational technology research on informal learning environments', Contemporary Educational Technology, vol. 1, no. 1, pp. 90-92.

Selwyn, N. (2007) "'Screw Blackboard ... do it on Facebook!": an investigation of students' educational use of Facebook', Proceedings from the Poke 1.0 - Facebook Social Research Symposium, London, pp. 1-23.

Selwyn, N. (2011) 'Web 2.0 applications as alternative environments for informal learning a critical review', Proceedings of the Alternative Learning Environments in Practice: Using ICT to Change Impact and Outcomes, London, UK, pp. 1-10.

Sheldon, P. (2008) 'Student favorite: Facebook and motives for its use', Southwestern Mass Communication Journal, vol. 23, no. 2, pp. 39-53.

Siemens, G. \& Weller, M. (2011) 'Higher education and the promises and perils of social network', Revista de Universidad y Sociedad del Conocimiento (RUSC), vol. 8, no. 1, pp. $164-170$.

Souleles, N. (2012) 'Phenomenography and elearning in art and design', Proceedings of the 8th International Conference on Networked Learning, Maastricht School of Management, Netherlands, April 2-4, 2012, [online] Available at: http://www.networkedlearningconference. org.uk/abstracts/koole_smposium.html

Vivian, R. (2011) 'University students' informal learning practices using Facebook: help or hindrance?', Communications in Computer and Information Science, vol. 177, pp. 254-267.

Webb, G. (1997) 'Deconstructing deep and surface: towards a critique of phenomenography', Higher Education, vol. 33, pp. 195-212.

\section{Appendix}

\section{Interview questions}

(1) How often do you use Facebook?

(2) What do you use Facebook for? What do you do when you are logged in Facebook?

(3) Do you think regular use of Facebook has any effect on your studies?

(4) Do you think Facebook can be used to help your studies?

(5) How do you feel if your teachers started using Facebook for teaching and learning?

(6) Do you know if there is any useful information for your studies in Facebook?

(7) Do you think Facebook provides a viable alternative to the traditional Graphic Design studio?

(8) How do you compare Facebook with the university's VLE? 